\title{
Spontaneous ventral urethral fistula in a young healty man and a modified surgical technique of urethral fistula repair
}

\author{
Ali Akkoc, MD; ${ }^{*}$ Ahmet Metin, $M D^{+}$ \\ *Department of Urology, Diyarbakir Education and Research Hospital, Diyarbakir, Turkey; †Department of Urology, Abant lzzet Baysal University Faculty of Medicine, Bolu, Turkey
}

Cite as: Can Urol Assoc J 2012;6(6):E280-E282. htrtp://dx.doi.org/10.5489/cuaj.12005

\section{Abstract}

Urethral fistula is rare and is usually a complication of penile and urethral surgery. A few congenital cases have been reported. Also, one acquired spontaneous case in a diabetic man has been reported. We present the first case in the literature of a healthy man with a spontaneous ventral urethral fistula, with unknown etiology. We performed a modified technique of urethral fistula repair (four-layer technique).

\section{Introduction}

Urethral fistula is rare and usually a result of infectious complications, trauma or surgery. ${ }^{1}$ Acquired cases have been reported after blunt penile trauma or straddle injury, but the development of fistulas remains exceptional even under these circumstances. Even after complex hypospadia repair, it is reported in no more than $10 \%$ of cases. ${ }^{2,3}$ Isolated congenital anterior uretrocutaneous fistula is extremely rare and few cases have been reported. ${ }^{4}$ Congenital urethral fistulas are seen as rare anomalies, usually in combination with anorectal malformations. ${ }^{5}$ To our knowledge, no case of a spontaneous ventral urethral fistula in a young healthy man has been reported to date. Fistula repair is individualized and includes simple multilayer fistula closure; it may involve the techniques employed in hypospadias surgery or more complex reconstruction of the distal urethra and glans. ${ }^{6}$

\section{Case report}

A 21-year-old male was admitted to the urology department because of an additional opening on the ventral side of the penis, which was present for 7 years (he was voiding through both openings). His medical history included a circumcision at age 3; he had no other medical conditions. A small pimple appeared on the ventral penis 2 months before the fistula occurred. Physical examination revealed bilateral normally positioned testes, a normal glans, no chordee, a normal external urethral meatus and an additional opening on the ventral side of the penis. Distal urethra was patent and surrounded by spongiosum. The fistula was about $1 \times 1 \mathrm{~cm}$ in diameter (Fig. 1). A 14 Foley urethral catheter was passed through the fistula, which came out of the glandular meatus suggesting an intact distal urethra. His systemic examination was not significant for any specific disorder. Blood urea nitrogen and serum creatinine levels were 11.6 and $0.9 \mathrm{mg} /$ $\mathrm{dL}$, respectively. Serum glucose level was $84.8 \mathrm{mg} / \mathrm{dL}$ and his white blood cell count was $6.8 \times 10^{9} / \mathrm{L}$. The urine analysis and abdominal sonography were normal.

Multilayer fistula closure was planned because the fistula tract was large. A circumferential incision was made around the fistula, and the urethral wall was dissected from the surrounding tissue. The dartos flap from the lateral side and the skin flap from the proximal side of the fistula were created (Fig. 2). The fibrous fistula tract was excised and the laceration was closed in two layers (urethra and corpus spongiosum) with $6 / 0$ vicryl sutures, while the catheter was inside (Fig. 3). The first layer was the urethral edge and the second layer was the spongious body. The lateral dartos fleb was sutured with $5 / 0$ vicryl on the closed fistula and the proksimal skin fleb was sutured with $4 / 0$ vicryl on the dartos fleb (Fig. 4). The fistula was closed tension-free in four layers. A 14 Foley catheter was left in place in the bladder for drainage. On removal of catheter on postoperative day 20, the fistula healed completely. After the 3-month follow-up, the patient had normal voiding, with no recurrence.

\section{Discussion}

Urethral fistulas are rare and their pathogenesis are usually due to infections, injuries or previous surgery (e.g., urethroplasty). ${ }^{1}$ To our knowledge, one case of a spontaneous ventral urethral fistula, related to poorly controlled diabetes, has been previously reported. ${ }^{7}$ In our case, the patient was completely healthy, with no other medical conditions. 


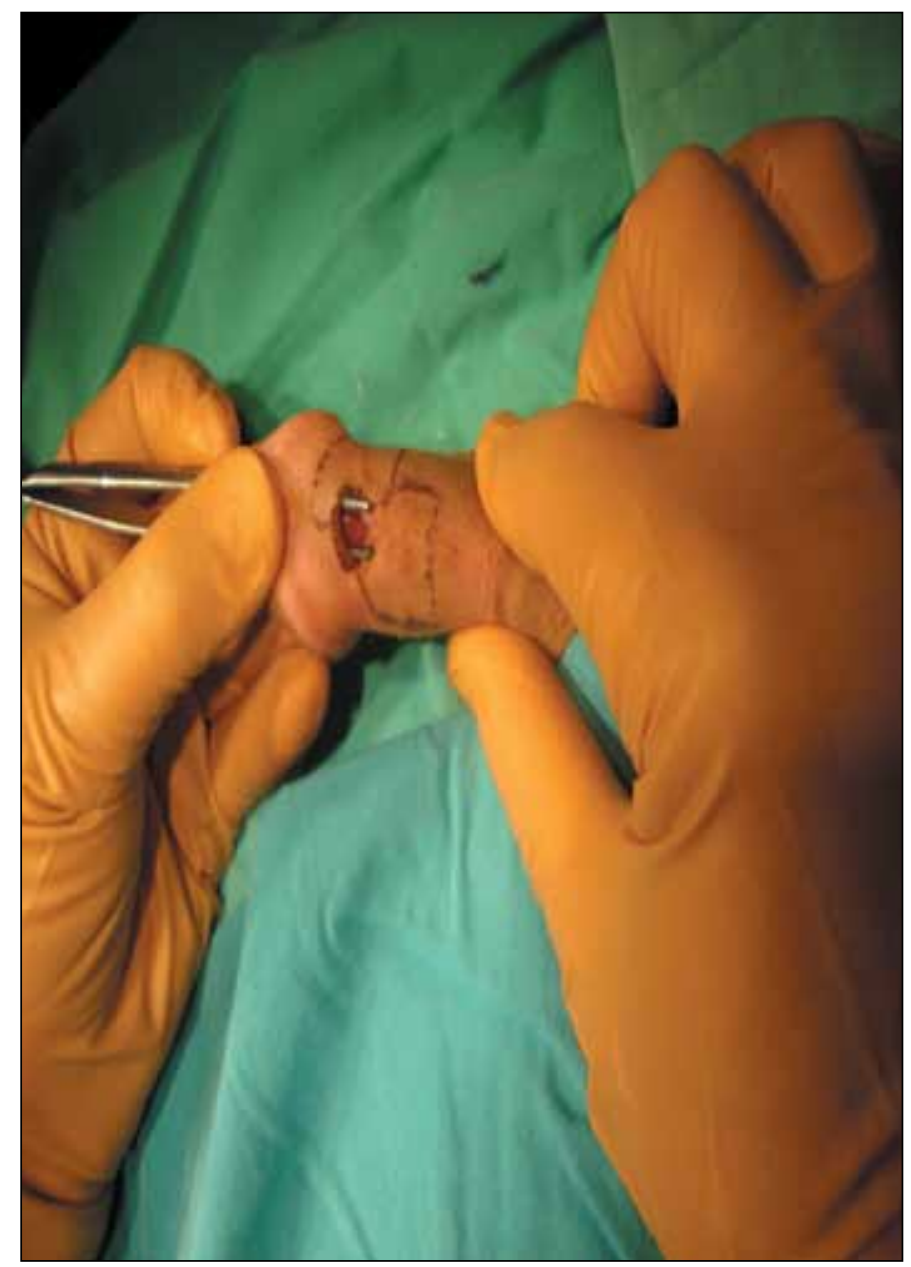

Fig. 1. The urethrocutaneous fistula on the ventral side of the penis.

Urethral fistula is a rare complication of penile and urethral surgery. A few congenital cases have been reported. ${ }^{4}$ In cases of an isolated fistula with intact spongiosum, repair with local flaps is sufficient. However, if the fistula is associated with deficient distal urethra, spongiosum, associated chordee or hypospadias, then formal hypospadias repair is recommended. ${ }^{8}$ There are different surgical options. Various techniques are proposed to repair these fistulas, including primary closure via Thiersch-Dupley urethroplasty, turned down flap urethroplasty and pedicled island tube, or onlay urethroplasty. ${ }^{9}$

The size and location of the fistula and status of the surrounding skin usually determine the optimum technique. ${ }^{10}$ It is believed whenever good penile skin is available, it should be used as the first choice.

\section{Conclusion}

We present a spontaneous ventral urethral fistula, with unknown etiology, in a healthy man. We used a modified

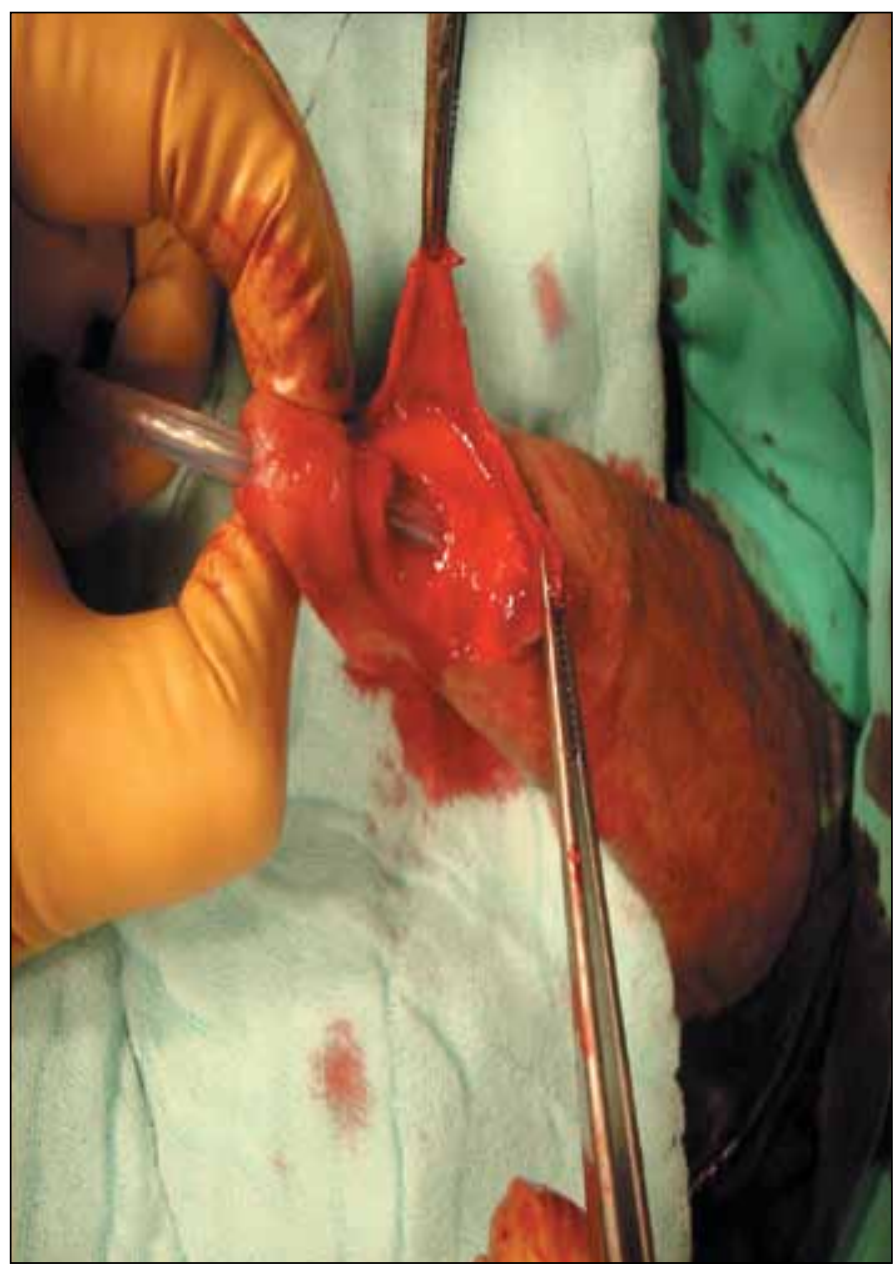

Fig. 2. The dartos flap from the lateral side and the skin flap from the proximal side of the fistula.

surgical technique of urethral fistula repair (the four-layer technique).

Acknowledgement: We thank Mrs. Gulsah Akkoc, the English Language Teacher of Koc Primary School, for revising our manuscript.

Competing interests: None declared.

This paper has been peer-reviewed.

\section{References}

1. Lau JT, Ong GB. Subglandular urethral fistula following circumcision: repair by the advancement method. J Urol 1981;126:702-3.

2. Ochsner MG, Joshi PN. Urethrocavernosus fistula. J Urol 1982;127:1190.

3. Amukele SA, Stock JA, Hanna MK. Management and outcome of complex hypospadias repairs. J Urol 2005;174:1540-2. http://dx.doi.org/10.1097/01.ju.0000176420.83110.19 


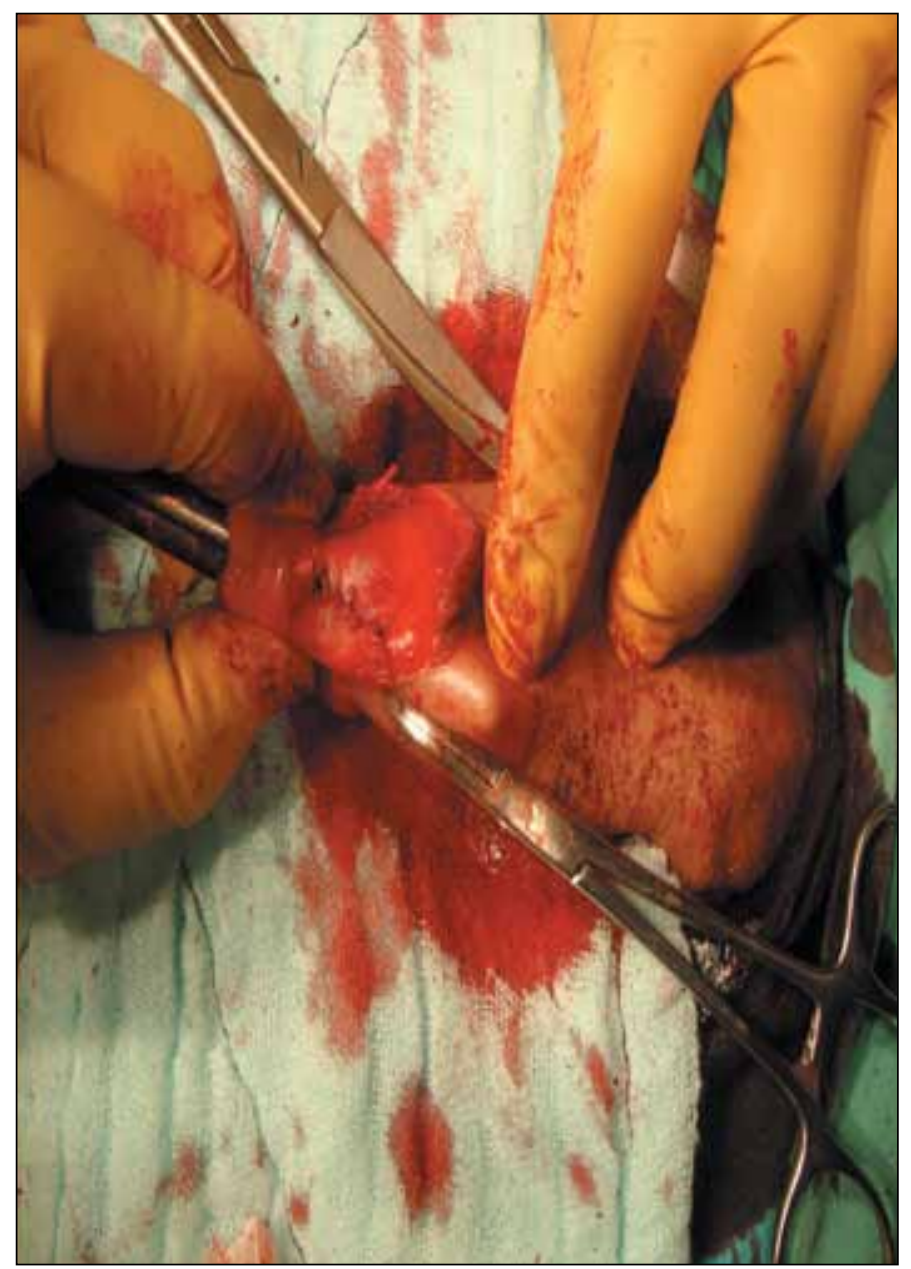

Fig. 3. The fistula closed in two layers (urethra and corpus spongiosum).

4. Chen Q, Xiao WL, Jiang YM, et al. Adult isolated congenital anterior urethrocutaneous fistula. Urol Int 2011;86:361-4. http://dx.doi.org/10.1159/000321920

5. Akman RY, Cam K, Akyuz 0, et al. Isolated congenital urethrocutaneous fistula. Int I Urol 2005;12:417-8. http://dx.doi.org/10.1111/i.1442-2042.2005.01050.x

6. Rashid KA, Kureel SN, Tandon RK. Congenital anterior penile isolated urethrocutaneous fistula: a case report. Afr J Paediatr Surg 2008:5:52-3. http://dx.doi.org/10.4103/0189-6725.41640

7. Denzinger $S$, Wieland WF, Burger $M$, et al. Spontaneous ventral urethral fistula in a young diabetic man: a case report. J Med Case Reports 2007;1:80. http://dx.doi.org/10.1186/1752-1947-1-80

8. Welch KJ. Hypospadias. In: Ravitch MM, Welch KJ, Benson CD, Aberdeen E, Randolph JG. Pediatric surgery. Year book Medical, Chicago; 1979:353-1376.

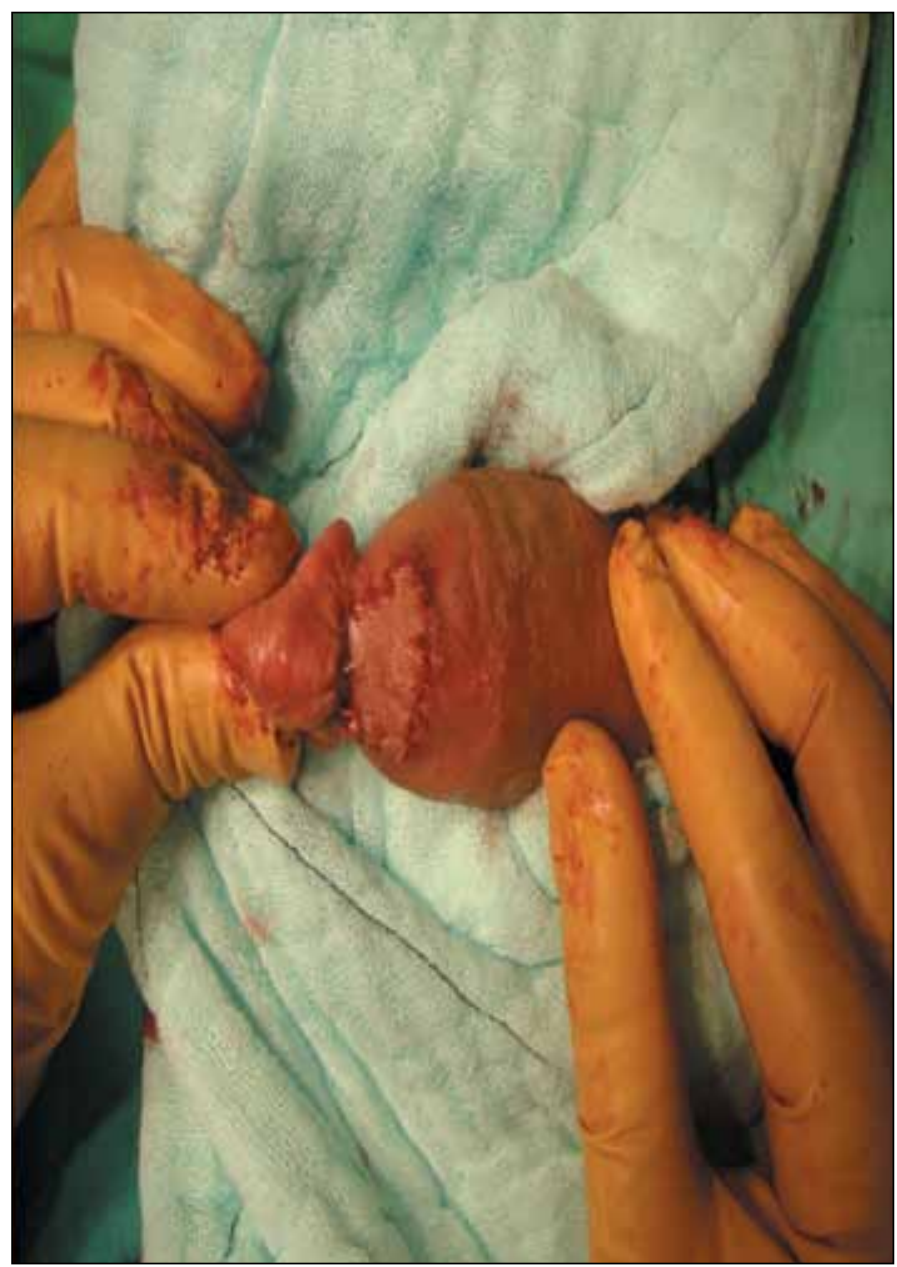

Fig. 4. The fistula closed by lateral dartos fleb and proximal skin fleb.

9. Agarwal P. Congenital anterior urethrocutaneous fistula revisited. Indian J Plast Surg 2004;37:64-6.

10. Kiss A, Pirot L, Karsza L, et al. Use of buccal mucosa patch graft for recurrent large urethrocutaneous fistula after hypospadias repair. Urol Int 2004;72:329-31. http://dx.doi.org/10.1159/000077687

Correspondence: Dr. Ali Akkoc, Department of Urology, Diyarbakir Education and Research Hospital, Diyarbakir, Turkey; fax: +90 41225891 93; aliakkoc@gmail.com 